Revista Iberoamericana, Vol. LXXIII, Núm. 220, Julio-Septiembre 2007, 471-486

\title{
DANDIES, INDIOS Y OTRAS REPRESENTACIONES DE LA MASCULINIDAD EN MANUEL GONZÁLEZ PRADA
}

\author{
POR \\ Ana Peluffo \\ University of California, Davis
}

\begin{abstract}
Si en las miríadas de mundos
Existe un mundo viril,

Si hay un astro de rebeldes,

Oh muerte, llévame ahí.
\end{abstract}

Manuel González Prada, Trozos de Vida

A lo largo de los últimos años la crítica latinoamericana ha venido desarrollando un productivo debate sobre las genealogías de la modernidad euro-occidental en sus múltiples transplantes y procesos transculturalizadores. La atención que se prestó a los desajustes de una modernidad positivista en el contexto periférico latinoamericano no ha dejado demasiado lugar para el estudio de los excesos sentimentales que corroyeron la voluntad racionalizadora en el siglo xIx. ${ }^{1}$ En el caso del Perú, el sentimentalismo lacrimógeno de filiación romántico-victoriana se colocó del lado de la esfera femenina, sin prestar atención a su vertiente masculina. La figura de Manuel González Prada se asocia en general con una visión anti-sentimental de la nación y de sus otros (mujeres, indios), conceptualizada teóricamente a partir de un corpus ensayístico definido como "latigueante”, “combativo”, “acerado” y “demoledor”. ${ }^{2}$ El estatus canónico que González Prada adquiere en la literatura peruana del siglo XIX coincide con la marginalización de un corpus poético que incluye tres volúmenes: Minúsculas (1901), Exóticas (1911) y Baladas peruanas (publicadas póstumamente en 1935). ${ }^{3}$ En este trabajo me propongo establecer un diálogo

\footnotetext{
${ }^{1}$ La excepción notable a este silencio sobre el sentimentalismo latinoamericano es El imperio de los sentimientos de Beatriz Sarlo en el que se hace un estudio socio-histórico de la literatura periódica no culta publicada en Buenos Aires en las primeras décadas del siglo xx. Este corpus narrativo apelaba, según la autora, a un público mayormente femenino.

${ }^{2}$ Dice por ejemplo Riva Agüero: "González Prada es un prosista de combate. Ataca con valentía y rudeza, lucha cuerpo a cuerpo, despierta pasiones, suscita odios y rencores, se enardece en la refriega, fascina por sus metáforas atrevidas y plásticas y por la concisión y rapidez de su vibrante frase" (235).

${ }^{3}$ Ferrari apunta con desconcierto el olvido en el que se ha sumido la poesía de González Prada por oposición a la prosa en la cultura peruana contemporánea. Refiriéndose a una entrevista hecha por la revista Hueso húmero de Lima en 1979 indica que "sólo once de los sesenta y cuatro escritores y críticos que respondieron incluyen a Manuel González Prada (1848-1918) entre los diez mayores poetas del Perú”, de lo que concluye: “hoy la poesía de Prada gusta poco o se lee poco” (317).
} 
intergenérico entre los dos González Prada: el ensayista y el poeta, a partir del substrato sentimental lírico sobre el que se superpone la rudeza viril de los ensayos. Trataré de demostrar que el sentimentalismo andino de las Baladas peruanas le sirve a González Prada para construir un modelo de masculinidad "blanca” e hiperviril que coloca el exceso lacrimógeno del lado de la subjetividad indígena. A su vez, los frecuentes cruces y tensiones entre la masculinidad serrana, que él imagina débil y femineizada, y un ideal de subjetividad europeo-que a veces se define como dandismo y otras como marcial, racional y guerrero- se articulan con la necesidad pradiana de redefinir las masculinidades de fin de siglo en una situación histórica de crisis.

En un panegírico que González Prada pronunció en 1888 en el entierro de su amigo Luis Márquez, el autor de Páginas libres se plegaba a una idea estoica de la virilidad en la que el gran tabú era hacer de los sentimientos un espectáculo. Refiriéndose a la necesidad histórica de no derramar lágrimas públicas por las catástrofes nacionales, González Prada reflexionaba sobre el concepto de la masculinidad republicana en una sociedad traumatizada por la pérdida de la Guerra del Pacífico (1879-1883): "Los héroes de los antiguos tiempos lloraban como niños y mujeres; los hombres de hoy no sabemos, no queremos llorar, y cuando sentimos que las lágrimas pugnan por subir a nuestros ojos, realizamos un esfuerzo para detenerlas en lo íntimo del corazón” (Páginas 34). Lo que se proponía en este ensayo era anclar el heroísmo masculino en una forma de racionalidad viril que le sirviera al sujeto nacional para protagonizar los procesos de la modernización y la urbanización. Para entrar en la corriente de progreso las naciones debían dejar atrás las sensibilidades lacrimógenas que hacia fin de siglo habían comenzado a colocarse del lado de la femineidad y de la otredad racial. El verdadero líder de la secularización modernizadora era en los ensayos de González Prada un sujeto masculino que escondía sus emociones y que rendía culto a la privacidad del yo. Dentro de esta poética de contención se establecía una relación oximorónica entre afectividad y racionalización. El culto casi religioso que Prada profesaba con respecto al racionalismo de los enciclopedistas europeos queda metaforizado en una conocida frase de Minúsculas que Mariátegui coloca a su vez como epígrafe de sus reflexiones sobre González Prada: “Guerra al menguado sentimiento, culto divino a la razón” (citado en Mariátegui 233).

En las meditaciones obsesivas de González Prada sobre la necesidad de virilizar a la comunidad nacional en todos sus niveles ocupa un lugar importante la figura de un sujeto masculino femineizado al que se construye como contramodelo del heroísmo. La figura de Boabdil, el rey moro que lloró públicamente por la pérdida de Granada, se utilizaba también en el discurso del Politeama como un arquetipo arcaico de la masculinidad (en términos de Raymond Williams) frente al que se construía una identidad emergente anclada en "la cólera viril” del patriotismo (47). El discurso del Politeama culminaba con un llamado a la rabia colectiva, un sentimiento que por sus asociaciones con la agresividad “masculina” parecía acatar la ideología liberal de la separación de las esferas que compartimentalizaba los afectos por género, jerarquizándolos en términos de público/ privado, cólera/tristeza, razón/sentimiento, masculino/femenino:

Verdad, hoy nada podemos, somos impotentes; pero aticemos el rencor, revolvámonos en nuestro despecho como la fiera se revuelca en las espinas; y si no tenemos garras para 
desgarrar ni dientes para morder, ¡qué siquiera los mal apagados rugidos de nuestra cólera viril vayan de cuando en cuando a turbar el sueño del orgulloso vencedor! (48)

Según González Prada, lo que se necesitaba en el Perú postbélico, traumatizado por la pérdida de la guerra, no eran hombres que llorasen como lo habían hecho "los románticos", sino hombres hercúleos que acabasen con "el abatimiento del ánimo cobarde” y "las quejas del pecho sin virilidad” (46). ${ }^{4}$ La voluntad patriótico-didáctica del ensayo que se leía con el objeto de hacer una colecta para recuperar Arica y Tacna de manos de los chilenos se traducía en la necesidad de construir héroes viriles para la nación que fueran como Grau, Bolognesi o el Cid, pero no como Boabdil. Para restituir la dignidad perdida del Perú había que superar la “ingénita mansedumbre del carácter nacional” en un concepto utópico de nación que buscaba homogeneizar a la comunidad por medio de valores que en las culturas occidentales se asignaban al ámbito masculino (agresividad, competencia, rivalidad) (49). En este sentido, la forma de incorporar al indígena al concepto de la peruanidad era convertirlo en un sujeto marcial que pudiera defender valerosamente la nación. Aunque González Prada llegaría a una interpretación revolucionario-anarquista del "problema indígena" recién en 1904, en algunos pasajes del discurso se apuntaba ya hacia la necesidad de "armar” y virilizar al indígena, para convertirlo no en un revolucionario sino en un rudo soldado que sirviera a los intereses de una patria en peligro: "Cuando tengamos pueblo sin espíritu de servidumbre, [...], recuperaremos Arica y Tacna, y entonces y sólo entonces marcharemos sobre Iquique y Tarapacá” (46). En este caso, sin embargo, no es beneficio de una cultura indígena amenazada por la racionalización moderna, sino de la república, que se propone "peruanizar" al hombre andino, tomando como modelo al soldado ideal de la revolución francesa: “Con las muchedumbres libres aunque indisciplinadas de la Revolución, Francia marchó a la Victoria; con los ejércitos de indios disciplinados y sin libertad, el Perú irá siempre a la derrota” (44). El carácter didáctico del ensayo se reflejaba en el hecho de que no era su

\footnotetext{
${ }^{4}$ Denegri señala con acierto la relación conflictiva de González Prada con la literatura sentimental de los románticos que todavía estaba siendo utilizada en el Perú de la posguerra por las escritoras de la generación del setenta: "Entre las cosas que detestaba el maestro González Prada ocupaba un lugar visible la literatura lacrimógena y sentimental de los antiguos románticos, cuya prosa 'remilgada', 'anémica', ‘afeminada', e ‘impotente’ encarnaba al Perú emasculado de la posguerra. La hasta aquí celebrada generación romántica se convertiría en adelante en un símbolo cultural del fracaso histórico de un país que, parafraseando a González Prada, no había caído valientemente como un gladiador, sino que se había desmayado como una cortesana, sin virilidad alguna” (135). ${ }^{5}$ También en "Nuestros indios" González Prada enfatiza la necesidad de "virilizar" al sujeto andino cuando dice: "La condición del indígena puede mejorar de dos maneras: o el corazón de los opresores se conduele al extremo de reconocer el derecho de los oprimidos, o el ánimo de los oprimidos adquiere la virilidad suficiente para escarmentar a los opresores. Si el indio aprovechara en rifles y cápsulas todo el dinero que desperdicia en alcohol y fiestas, si en un rincón de su choza o en el agujero de una peña escondiera un arma, cambiaría de condición, haría respetar su propiedad y su vida” (Horas 343, énfasis mío). Pese a la intención revolucionaria de este pasaje, subyace en él un substrato positivista que no respeta las tradiciones andinas (las fiestas) y que pone en circulación el estereotipo de un indígena pasivo y atontado por el alcoholismo. La imagen de un indígena
} 
autor el que lo leía sino un niño (porque, según Luis Alberto Sánchez, González Prada era tímido y tenía la voz demasiado "suave”, Mito 17) y que la audiencia estaba formada mayormente por escolares, es decir por los futuros ciudadanos de la patria. La consigna utópica sobre la necesidad de evitar la desmasculinización de la comunidad nacional era tajante. Dice en un momento el sujeto enunciante de Páginas libres: "Niños, sed hombres [...] ¿Por qué desesperar? No hemos venido aquí para derramar lágrimas sobre las ruinas de una segunda Jerusalén, sino a fortalecernos con la esperanza. Dejemos a Boabdil llorar como mujer, nosotros esperemos como hombres" (46).

El deseo pradiano de virilizar el concepto de la virtud republicana encuentra un punto de cruce con las reflexiones de Martí sobre la construcción de masculinidades en el siglo XIX. En uno de sus primeros poemas titulado “¿Qué me pides? ¿lágrimas?”, Martí también había recurrido a la figura de Boabdil, el antihéroe de la reconquista que "lloró con lágrimas de mujer lo que no supo defender como un hombre". ${ }^{6}$ Construido a manera de un tenso diálogo entre un sujeto lírico estoico y un tú femineizado que trata perversamente de hacer llorar al yo, se juega en el poema con la idea de encubrir y descubrir las lágrimas:

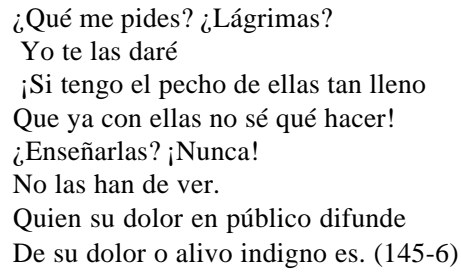

No ser como el "Boabdil impuro” al que Martí hace referencia en la última estrofa del poema (“¡Vuélvete atrás-coqueta de la pena!/¡Boabdil impuro, flaca Magadalena!”) se vuelve una consigna para el yo poético que plantea la necesidad de guardar las lágrimas, consideradas como femeninas, dentro de la interioridad de un yo construido como estuche o carcaza. En uno de los poemas de Trozos de vida (1933), publicado póstumamente, González Prada hace eco fraternal de las preocupaciones martianas sobre sentimentalismo y masculinidad, cuando invoca la necesidad de proteger la "sensibilidad amenazada" (Montaldo) de los aristócratas del pensamiento de los cambios provocados por la democratización cultural. ${ }^{7}$ Dice el yo poético, en diálogo ahora con un lector implícito masculino:

alcohólico que moviliza a González Prada ya había sido subvertida por Clorinda Matto de Turner en Aves sin nido (1888). En esta novela son las autoridades andinas blancas de Killac, más que los indios, las que aparecen fuera de control a causa del alcoholismo.

${ }^{6}$ Esta frase proviene de un anónimo romance español sobre la reconquista en el que la madre de Boabdil le echa en cara al hijo su falta de hombría/valentía en la defensa del reino de Granada.

${ }^{7}$ He desarrollado el tema del sentimentalismo masculino en José Martí en un artículo titulado "Homo-sentimentalismo, fraternidad y lágrimas en José Martí”. 


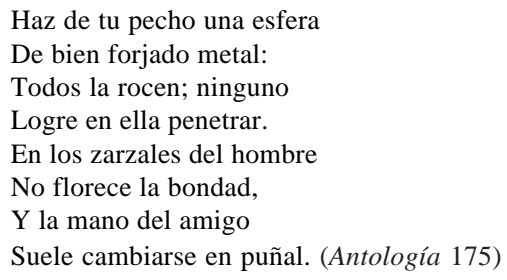

A diferencia del utopismo martiano en el que la fraternidad varonil constituye un refugio contra los embates de la modernización, en este poema González Prada invoca la necesidad de acorazar la frágil espiritualidad del poeta bajo la sólida consistencia del metal. Esta pose casi espartana a través de la cual el poeta se presenta ante el lector como "un cofre sellado" puede ser leída intertextualmente como una variación del "arielismo" magisterial de Rodó, especialmente en lo que respecta a la desconfianza frente a la “nivelación por lo bajo” que planteaba la democracia (véase Moraña).

La masculinización de la virtud propiciada por González Prada en los ensayos contrasta, sin embargo, con la estética del dandismo a la que parece plegarse en algunas de sus poesías. En su vertiente europea el dandismo era antisentimental ya que como lo apunta George Bryan Brummell, el creador de este mito en Inglaterra, "[e]l que quiera dominar [...] no debe dejarse comprometer por los sentimientos” (Hinterhaüser 68). Por otro lado, también Baudelaire hacía referencia a la frialdad deseada de los dandies cuando decía que estos debían responder con una sonrisa a los suplicios del sufrimiento. ${ }^{8}$ Dentro del culto al dandismo, la famosa frase de Baudelaire "la femme est naturelle, c'est-à-dire abominable" (Journaux 53) ilustra la misoginia de este mito finisecular. La hostilidad del dandy ante el sexo opuesto estaba basada en un proceso de fetichización de lo artificial y en un repudio absoluto al "primitivismo natural” con el que se asociaba en su función reproductora al sujeto femenino. Desde una perspectiva ideológica dominante, el carácter instintivo del sujeto femenino lo acercaba al primitivismo intuitivo de las culturas indígenas. Por otro lado, aunque los dandies rechazaban a la mujer por sus connotaciones sexuales-maternales buscaban apropiarse del lugar que ellas ocupaban como voraces consumidoras de refinamiento y modas. De ahí que estos protagonistas del decadentismo europeo defendieran el derecho de ser, como ellas, bellos, refinados y coquetos. Los verdaderos dandies debían vivir y dormir, según Baudelaire, delante del espejo (54). En el caso de González Prada, la estética parnasiana importada de Francia se adapta, no solamente a su corpus poético, sino también a su porte físico. ${ }^{9}$ La obsesión con el buen

\footnotetext{
8 “Un dandy peut être un homme blasè, peut être un homme souffrant; mais, dans ce dernier cas, il sourira comme le Lacédémonien sous la morsure du renard” ("Le peintre...” 227)

${ }^{9}$ Sánchez hace referencia al dandismo pradiano cuando dice: "La arrogancia de porte de Prada, su atildamiento en el vestir, denuncian al 'fashionable', ‘dandy' o elegante de vieja cepa” (Mito 13). Dado que los dandies eran extremadamente individualistas, Sánchez trata de matizar la crítica a la frivolidad de Prada con la siguiente sentencia. “Los ‘dandies’ se distinguían de la mediocridad por su conducta singular, pero eso no les impedía echarse en brazos del pueblo, como Alcibíades, el gran demagogo ateniense” (14).
} 
vestir se hace evidente en algunos retratos que aparecen como portada en sus colecciones de poemas. En una fotografía incluida en Grafitos (1937, póstumo), González Prada demuestra que no era enemigo del espejo y que seguía fielmente, como los dandies finiseculares porteños (Lucio Mansilla, Miguel Cané) los últimos dictados de las modas parisinas. La imagen de González Prada posando en un café, mientras moja una masita en una copa de licor, invita entonces a una reflexión sobre la latinoamericanización del dandismo en un contexto de transculturación..$^{10}$ Aunque el escenario elegido apunta a una cotidianeidad estructurada alrededor del ejercicio de rutinas placenteras; la actitud patricia y glacial de un González Prada vestido de levita, corbata blanca y bigotito profesionalmente peinado por un coiffeur, apela a un lector igualmente urbano y refinado para el que no va a dejar de pasar desapercibida su elegancia y distinción.

Los dandies usaban la ropa como una barrera que los separaba de la vulgaridad de su medio. Sin embargo, como bien lo indica Baudelaire, el dandismo no era tan sólo una pose frívola relacionada con la teatralidad de la moda, sino más bien una actitud del espíritu asumida por las almas elegidas de la cultura, acorraladas por el avance del materialismo. Los dandies practicaban entonces "el aristocrático arte de disgustar" en un entorno cultural mediocre y burgués al que despreciaban. ${ }^{11}$ Aquí cabe recordar que González Prada pone en práctica este deseo aristocrático desde la plataforma de los ensayos y que fue tal vez por eso una de las figuras más admiradas y odiadas de su tiempo. Como bien lo indica Mariátegui en Siete ensayos sobre la realidad peruana, González Prada fue más un “acusador” del pasado colonial que un "realizador" o constructor de utopías (232). Su legado a las nuevas generaciones residió, en este sentido, no en un programa político coherente del que siempre careció, sino en su "rebeldía” y en "la viril exaltación del esfuerzo y de la lucha” (237). De esta forma, se puede decir que las imprecaciones de González Prada contra la iglesia, sus despiadados juegos verbales y los agresivos chistes y aforismos contra la frailocracia limeña o el colonialismo español tiñen de un cariz combativo esta estética parnasiana que celebraba, en su vertiente francesa, la idea del arte por el arte. Es entonces al entrar en contacto con el nuevo contexto, que el dandismo se transforma en una de esas mitologías "fuera de lugar” cuyas complicadas genealogías recorre Roberto Schwartz en Misplaced Ideas (1992). En manos de González Prada el dandismo aristócratico de Georg Brummel o el más marginal y desclasado de Baudelaire, se convierte en un arma de combate con la que defender a capa y espada los principios de la secularización y la modernización.

El cosmopolitismo de los dandies latinoamericanos era producto del ennui que les suscitaba la mediocridad de una cultura colonial apegada todavía a los modelos literarios españoles. En un poema de Minúsculas titulado justamente “Cosmopolitismo” González Prada habla de la fatiga y el cansancio que provocan en el sujeto lírico "[e]l suspirar

\footnotetext{
${ }^{10}$ En El cuerpo del delito Josefina Ludmer hace un lúcido análisis del dandismo en el Río de la Plata a partir de las diferencias entre el dandismo europeo y el latinoamericano (46-56; 102-5).

11 "El placer aristocrático de disgustar" se hace presente no solamente en los ensayos sino también en una colección epigramática de chistes verdes sobre curas, titulada Presbiterianas (1909) que González Prada publicó bajo seudónimo. Aquí el deseo de escandalizar residía en la sexualización que Prada hacía de los padres de la iglesia.
} 
mirando eternamente / Los mismos campos y la misma gente, / Los mismos cielos y la misma bruma!” (Antología 55). Los deseos de acabar con el infantilismo colonial de la tutela peninsular llevan a González Prada a buscar ritmos y formas de otras partes de Europa (francesas, alemanas e italianas) con las que poetizar el referente nacional. ${ }^{12}$ En este sentido se establece un productivo cruce entre el cosmopolitismo de su aparato formal estructural y el referente peruano de ensayos y poemas. Dentro de este proceso de importación cultural, González Prada recurre a metáforas naturalistas para hacer frecuentes diagnósticos del “oprobio” nacional. El cientificismo de su mirada de voyeur se forma entonces a partir de la metáfora de la herida, porque en el Perú republicano "donde se aplica el dedo brota pus”. Por otro lado, en un poema de Libertarias (1938, póstumo), titulado "El Perú", el yo-dandy atacado de un hastío o ennui existencial de filiación baudelairiana, transfiere a la poesía los procedimientos literario-científicos de la prosa naturalista de Zola:

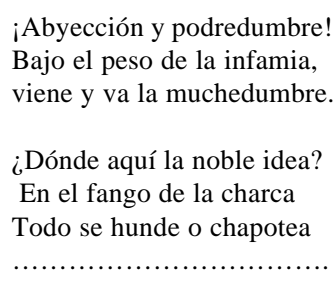

Busco luz, y busco en vano;

Aire quiero, y sólo aspiro

Bocanadas de pantano.

Y si aquí rodó mi cuna,

Soy aquí tan extranjero

Como en Londres o en la Luna.

A mi pueblo y a mis gentes,

¿Qué me liga, qué me enlaza?

Yo me siento de otro mundo,

Yo me siento de otra raza. (Antología 280-1)

¿Cómo reconciliar entonces la celebración de la globalización cultural, en poemas como éste, con el chauvismo de los ensayos? Al mismo tiempo, el deseo casi paranoico de huir de la mediocridad de las muchedumbres desdice la idea de Mariátegui de que González Prada “no desdeñó nunca a la masa” porque "reivindicó siempre su gloria oscura” (229). La utopía cosmopolita de González Prada se pone en práctica a nivel

\footnotetext{
${ }^{12}$ González Prada traduce a Goethe, Shelley y Richepin. También lee a Coleridge, Heine y Renan. Uno de los rasgos distintivos de su producción poética es la experimentación con formas métricas y estróficas de diferentes partes de Europa, fundamentalmente de Alemania, entre las que figuran baladas, trioletes, pantums, rondeles, espenserinas y villanelas.
} 
biográfico cuando éste decide establecerse en París durante siete años luego de haber fundado un partido político llamado La Unión Nacional. ${ }^{13}$

Uno de los aspectos más amenazantes del proceso de la democratización cultural que tuvo lugar a fines de siglo fue la emergencia en la república de las letras de la primera generación de mujeres letradas en el Perú. En la década del setenta, cuando González Prada escribe las Baladas peruanas, aparecen novelas y narraciones periódicas editadas por mujeres que llegan a un público masivo a través de estrategias sentimentales. ${ }^{14}$ Los periódicos de la época estaban plagados de poemas por los que circulaba "un aluvión de lágrimas y de tinta” (Sánchez, La literatura 115). Era una literatura mayormente fúnebre, a veces consolatoria y de circunstancia, en la que se lloraba por madres, hijos y esposas muertos. Por otro lado, aun cuando algunas de las ideas de González Prada sobre la necesidad de secularizar y modernizar al sujeto femenino republicano, fueron, como lo indica Javier Lasarte, progresistas para la época, sus reflexiones sobre la masculinidad en relación a la literatura no dejan de ser problemáticas. Así por ejemplo en un artículo sobre Juan Valera, González Prada acusaba a su autor de producir una literatura afeminada que carecía de “pujanza varonil” (Páginas 146). Las reflexiones de González Prada sobre literatura y género se dan por lo tanto en un contexto anárquico sexualmente hablando, en el que los letrados viven con gran alarma la feminización de los hombres y la masculinización de las mujeres. ${ }^{15}$ Dice González Prada en "Valera: Poeta y epistolario":

\begin{abstract}
Lombroso descubre en casi todas las literatas eminentes algo masculino, tanto en sus obras como en su fisonomía y acciones. [...] El escritor acostumbrado a las ceremonias de corte y a las genuflexiones de salón o antecámara, presenta muchas veces en su estilo la minuciosidad y meticulosidad de la mujer; cuando escribe, parece que borda o cose; su pluma concluye por adquirir la sutileza de la aguja. [...] Hay pues casos de inversión cerebral: hombres que escriben como mujeres, mujeres que escriben como hombres; y se expone a graves errores el crítico que por la forma de un libro intente descubrir el sexo del autor. Así, atribuiríamos a un hombre los poemas filosóficos de Madame Ackermann y las disquisiciones científicas de Clemence Roger; por el contrario, atribuiríamos a una mujer los versos de Grilo y la prosa de Valera. (146)
\end{abstract}

En un contexto en el que empezaba a visualizarse una incipiente feminización de la cultura letrada, los poetas se hallaban en una posición de marginalidad que los colocaba en una situación en muchos sentidos análoga a la de las mujeres. Esta situación se agrava por la expulsión de los letrados de la conducción política del Estado, proceso cuyas implicancias para la construcción de proyectos nacionales y culturales a fin de siglo ha

\footnotetext{
${ }^{13}$ En casi todos los estudios sobre González Prada se le critica y reprocha este alejamiento temporario del Perú, que es vivido por sus críticos como una traición a la patria (véanse Sánchez, Salazar Bondy, Tamayo Vargas).

${ }^{14}$ Para más información sobre la producción cultural de las escritoras peruanas de esta generación puede consultarse Denegri. También, para la cuestión del periodismo femenino resulta útil la antología de Aída Balta.

${ }^{15}$ El concepto de la “anarquía sexual” en relación a la redefinición genérica que se da en las culturas de fin de siglo es de Elaine Showalter.
} 
estudiado Julio Ramos en Desencuentros de la modernidad en América Latina. La cercanía socio-cultural de los poetas con la cultura femenina provoca, por ende, una serie de conflictos y contaminaciones a las que se responde en muchos casos con propuestas ideológicas conservadoras y masculinizantes que buscan restituir las viejas barreras entre los géneros (femenino/masculino, afectividad/razón, público/privado). ${ }^{16}$

La situación se complica por el hecho de que en el siglo xix se piensa el campo de la poesía como un ámbito femineizado en el que se rinde culto a las emociones. González Prada plantea la relación entre poesía y narrativa en términos de una batalla entre géneros tanto literaria como sexual. En un ensayo titulado "La poesía”, afirma la subalternidad del género lírico a partir de una idea de Chateaubriand según la cual "volverse poeta” equivale a "perder la fuerza del pensamiento" (Nuevas 63). Dice también que en los tiempos modernos la prosa "tiende a eliminar el verso, como el gas eliminó a la bujía, como la luz eléctrica va eliminando al gas” (64). Es en la prosa y no en la poesía, donde se concentra “toda la savia y toda la médula del pensamiento humano” (64). En este sentido, González Prada coloca a los poetas “con sus denigrantes lloriqueos” en una relación conflictiva con sus ideas sobre la modernidad. Poetas, mujeres y curas formaban para González Prada una contracultura sentimental que se oponía a los avances secularizadores del progreso y de la ciencia. Por sus asociaciones con la religión y lo sentimental estos grupos vivían según González Prada, no en el espíritu racional científico de la modernidad europea sino en el oscurantismo de la Edad Media, un espacio imaginado de irracionalismo y caos en el que ya Sarmiento había colocado en Facundo: civilización y barbarie (1845) a los gauchos y los indios. ${ }^{17}$ Para González Prada, entonces, la poesía se vuelve marginal y antiutilitaria, no solamente por su carácter femineizante, sino también porque en el período de la construcción nacional se necesita de la virilidad combativa de la prosa. En el poemaprólogo a Minúsculas titulado “Por la rosa” González Prada registra esta preocupación por la subalternización de los poetas en la época de la modernización desigual:

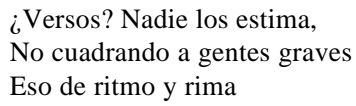

\footnotetext{
${ }^{16}$ González Stephan se refiere a las ansiedades que causaba el proceso "de dulcificación de las costumbres” que aparejaba la modernización en el imaginario masculino de la época. En este trabajo coincido con la idea de Stephan de que el discurso de la masculinidad beligerante-heroica habría sido una respuesta a lo que se percibía como una incipiente feminización de la cultura. Dice González Stephan: "La ciudadanía, entonces, devino en un sueño de camaraderías masculinas, hermanadas por la virtud y la belleza serena (la contención y el erotismo) como maneras que permitían negociar (desplazar y sublimar) el terror homosexual” (113).

${ }^{17}$ La dicotomía genérica entre el mundo viril de los ensayos, que es el de la esfera pública, y el más espiritualizado de la poesía, anclado en el interior doméstico, atraviesa también, como lo ha demostrado Julio Ramos en Desencuentros de la modernidad, el corpus martiano. De ahí que cuando en "Serie de artículos para la América” Martí establece una relación jerárquica entre imaginación y razón, asocia la primera con la poesía y dice: “La imaginación ofrece a la razón, en sus horas de duda, las soluciones que ésta en vano sin su ayuda busca. Es la hembra de la inteligencia, sin cuyo consorcio no hay nada fecundo" (Lasarte 41).
} 


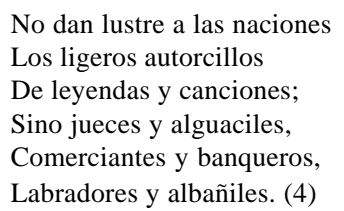

La visión genérico-jerárquica que González Prada tiene de la relación entre poesía y prosa es paradójica si se tiene en cuenta que en el corpus gonzález-pradiano la práctica poética excede a la ensayística. Por otro lado, en Minúsculas, González Prada plantea la necesidad de pensar el ámbito de la poesía como un refugio de la subjetividad letrada. Dice: "resignémonos en prosa, pero en poesía, combatamos por la azucena y la rosa". ¿Pero cómo hacían los poetas para mantener intacta la virilidad una vez que se adentraban en ese ámbito femineizado de azucenas, rosas y a veces orquídeas, una de las flores preferidas de los dandies de fin de siglo? ${ }^{18}$

En las Baladas peruanas, que González Prada nunca publicó en vida, se recurre a la retórica de las lágrimas para incorporar al hombre andino a la idea de la peruanidad. Lo que hace de las Baladas peruanas un texto sentimental y político al mismo tiempo es la atención que se presta en ellas al sufrimiento de los grupos marginales que queda estetizado con el propósito de conmover al lector. El motivo de la pérdida domina muchos de estos poemas, dando pie a un tono casi elegíaco por la desaparición de las glorias de la cultura incaica. ${ }^{19}$ Philip Fisher en Hard Facts (1985) ha demostrado los alcances políticos del sentimentalismo decimonónico anglosajón en el que se incorporan al mundo de la cultura personajes marginales que no piensan sino sienten (niños, retrasados mentales, campesinos, pobres). En la literatura sentimental se presta particular atención a los cuerpos de los grupos subalternos y a las "lágrimas sagradas" que fluyen de ellos. El indígena que González Prada fabrica en estos poemas es el equivalente peruanizado del noble sauvage de Rousseau. ${ }^{20}$ Es un sujeto que sufre por falta de libertad y cuya autoridad moral deriva de un primitivismo incontaminado por el materialismo y el progreso. Al igual que las mujeres, los indígenas imaginados por González Prada son sujetos colonizados incapaces de separar, como diría Baudelaire, el alma del cuerpo. A nivel temático, el material elegido para poetizar la realidad nacional son las leyendas indígenas incaicas y el trauma de la conquista, dos temas que Ricardo Palma había dejado mayormente

\footnotetext{
${ }^{18}$ Véase el poema “A una orquídea”, publicado en Exóticas, en el que González Prada compara al poeta con una orquídea. Dice en la última estrofa, refiriéndose a la flor: "Como poeta mudo y abstraído / Que en su alma eleva cántico sin voz, / Tú soñadora vives, entonando / El himno silencioso del color" (Antología 90).

${ }^{19}$ Cornejo Polar comenta en La formación de la tradición literaria que las Baladas peruanas serían de acuerdo a su propia calificación en su mayor parte indianista-románticas con alguna que otra indigenista, fundamentalmente "El Mitayo".

${ }^{20}$ Ver por ejemplo "El Mitayo", en el que las lágrimas del padre provocadas por "la injusta ley de los blancos" quedan convertidas en espectáculo, y "Origen del Rimac" en el que el torrente de lágrimas de "el viejo rey de la costa” pone fin a largos años de sequía (36-7).
} 
intocados en las Tradiciones peruanas. El espacio poético de las Baladas está por lo tanto marcado por claroscuros románticos en los que la agresividad se coloca siempre del lado del colonizador español y el sufrimiento del lado de los indios. Así por ejemplo en un poema de título irónico, “Caridad de Valverde”, se alude a los corazones de piedra de los españoles que no se conmueven por el sufrimiento de los indios. En otro poema titulado "La piedra cansada" se contrasta, por medio de la prosopopeya, la falta de humanismo de los españoles con el sentimentalismo de piedras animadas, capaces de llorar por los indios y solidarizarse con la cultura de los oprimidos.

Luis Alberto Sánchez, en la edición póstuma de las Baladas peruanas confiesa un cierto pudor al publicarlas, como si hacerlo fuera atentar contra la virilidad del "Maestro" o "Apóstol”, sacando a la luz no solamente el carácter descuidado de estos poemas que González Prada nunca retocó, sino también una sensibilidad “delicada” que su mismo autor trató de combatir en los ensayos de Páginas libres:

Hay quienes piensan que la edición de ciertas obras desconocidas u olvidadas de un autor prócer, constituye un atentado contra su Gloria. Creo lo contrario. Amo tanto la acción, la obra que se trabaja haciendo, que encuentro en cada error, en cada desacierto, la fuente espléndida de los aciertos subsiguientes y supervivientes. ("Prólogo” 19)

El sentimentalismo de las Baladas peruanas estaría según los críticos en las antípodas del carácter hiperviril y antisentimental de una prosa ensayística que se define a sí misma como “combativa” y “acerada”. Esta retórica de "propaganda y ataque” en la que las palabras funcionan como látigos o espadas fue según Salazar Bondy una de las más “puras y vigorosas” de la lengua castellana (10). En este sentido la idea de González Prada de que había que romper "el pacto tácito e infame de hablar a media voz" parece ajustarse más al positivismo de los ensayos que al sentimentalismo lacrimógeno de las baladas. Pero, ¿hay algún punto de cruce, ya sea estético o ideológico, entre el corpus poético y el ensayístico? ¿En qué medida los diferentes conceptos de nación, raza y masculinidad que González Prada promueve en el ámbito de la poesía y de la prosa están marcados por el año terrible de la guerra?

En un poema incluido en las Baladas peruanas titulado "Invención de la quena", González Prada invoca el cliché de la amada muerta, uno de los topoi preferidos de la poesía latinoamericana de fin de siglo para construir una forma de subjetividad indígena asociada con la producción poética sentimental. ${ }^{21} \mathrm{El}$ poema se inaugura con una escena necrofílica en la que un inca poetiza su incapacidad de llorar frente a la tumba de su amada. Los deseos de apelar a una retórica llorisqueante colocada del lado de lo femenino son racionalizados por el yo indígena de la siguiente forma:

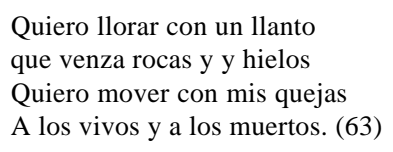

\footnotetext{
${ }^{21}$ He reflexionado sobre este problema en un artículo titulado "Decadentismo y necrofilia: El culto a la amada muerta en la poesía latinoamericana de fin de siglo”.
} 
Lo que se plantea en este poema es que la retórica de las lágrimas puede servir como estrategia de autorización de los poetas en una época en que como bien decía Salaverry (anticipándose a las preocupaciones pradianas y darianas sobre la falta de público para la poesía) la poesía era un género acorralado por los avances de la prosa. ${ }^{22} \mathrm{Al}$ igual que en la leyenda de Syrinx de la Metamorfosis de Ovidio en la que Pan hacía con el cuerpo de la amada una flauta, aquí el inca profana la tumba de su objeto de deseo para hacer con sus huesos un instrumento musical.

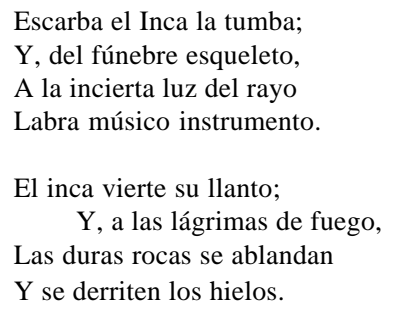

La asociación de la poesía con la androginia queda emblematizada por una fagocitación de la voz femenina en la que el poeta deviene una especie de caníbal de las emociones. Es decir: cuando el poeta construye el instrumento con los huesos de la amada, el cuerpo masculino del inca canibaliza una espiritualidad femenina de la que es sinécdoque la quena. La construcción de un sujeto masculino sentimental depende de la desaparición física de la amada y de la conversión de su cuerpo en alma. Aunque el poema subvierte el estereotipo del hombre racional que González Prada fomenta en los ensayos, la racionalidad de la voz poética queda intacta al colocar ese sufrimiento dentro de un cuerpo masculino indígena.

La representación de un indígena lloroso y suplicante, que leída desde el siglo xx nos resulta tan objetable, ocupa un lugar central en “¡Huatanay!”. Este poema se construye como un exposé de los abusos a los que se somete a los miembros más vulnerables de la comunidad nacional. Si en el corpus sentimental europeo hay una preocupación por el estatus dependiente de personajes a los que se busca dar la autonomía a través de un proceso de humanización (Fisher), aquí el indígena es un esclavo o bestia de carga al que el poeta se esfuerza por convertir en hombre.

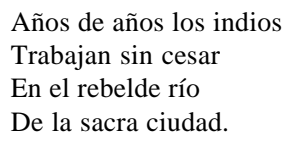

\footnotetext{
${ }^{22}$ En un poema titulado "Verso y prosa”, Salaverry reflexiona sobre la problemática recepción de la poesía en el Perú del siglo xix: "Llorad en vuestras arpas, trovadores/El pasado feliz... ¡ el mundo avanza!.../Derribar es la ley del universo!/Ya para vuestras rimas no hay lectores:/La bella prosa al porvenir se lanza,/y obscuro yace destronado el verso” (Sánchez Literatura 1005, énfasis mío).
} 


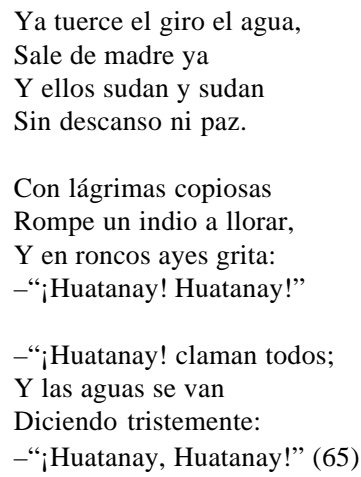

La alianza sentimental entre el hombre andino y su entorno queda cimentada por medio de un sistema de ecos en el que las lágrimas de los indígenas fluyen con la misma vitalidad que las aguas del río. Las culturas oprimidas visualizadas por González Prada responden a la marginalización aguda que padecen, de forma física más que racional (es decir llorando, o sudando). El animismo del poema se hace presente en la visión de una naturaleza benigna que actúa como campo de resonancia de las quejas del hombre andino.

Varios de los poemas de Baladas peruanas giran obsesivamente alrededor del fracaso de la relación heterosexual entre españoles e indias, relaciones que se interrumpen todas por medio de la muerte. En un poema titulado "La hija del Curaca” el filicidio paterno se vuelve una forma de impedir que la hija indígena se entregue a los brazos del "gentil conquistador”. Paradójicamente, este caso de violencia extrema está emprendido por el "amor" paternal en un poema que apunta a la necesidad de reafirmar el poder supremo de la masculinidad. En otro poema titulado “La india” la representación alegórica de la nación como una princesa incaica amenazada por la codicia sexual/material de los conquistadores escenifica a nivel poético la gran desconfianza que tiene González Prada con respecto a la ideología del mestizaje garcilaciano. En la alegorización que hace González Prada de la comunidad nacional, la muerte de los indígenas es preferible a la penetración nacional/ sexual española. Así, el poema "La india” metaforiza la leyenda de "Hima-Sumac" sobre el tesoro escondido de los incas, recurriendo al motivo literario de la inocencia indígena. La leyenda -que había sido narrativizada por Juana Manuela Gorriti en El tesoro de los incas (1870) y por Clorinda Matto de Turner en su obra teatral Hima-Sumac ${ }^{23}$ - cuenta la historia de una princesa incaica que ha heredado de sus padres la llave del tesoro escondido de los incas. El topos del tesoro oculto amenazado por la rapacidad de los conquistadores remite metafóricamente a una utopía incaica que se articula con una visión melancólica del pasado indígena de la nación. Aunque esta narración oral sobre un tesoro subterráneo circulaba en diferentes versiones por el campo intelectual, el poema de González Prada

\footnotetext{
${ }^{23}$ Esta obra de Matto de Turner se estrenó primero en Arequipa en1884 y luego en Lima en 1888. Es una obra musical incaísta escrita en la tradición del drama quechua Ollantay. Para más información sobre esta obra véase Berg.
} 
“masculiniza” a la mujer indígena a través de la práctica del delito. A diferencia de Matto de Turner y de Gorriti que paradójicamente hacen que un hombre mate al español en venganza por haber seducido a la indígena, aquí es la misma mujer indígena la que apuñala al español, en lo que parece un eco intertextual romántico de La cautiva de Esteban Echeverría.

La batalla entre sentimentalismo y estoicismo que se da en el corpus pradiano encuentra los ejes de su polarización en el ámbito de la prosa y la poesía. Sin embargo, muchas veces existen contradicciones internas dentro de los géneros. Así, por ejemplo, en un polirritmo sin rima titulado “Contra el dolor” y publicado en Exóticas, González Prada arremete contra "el morboso culto” al sufrimiento característico de la poesía sentimental del siglo XIx. El rechazo hiperbólico a la poetización del dolor que tan productivo le había resultado en las Baladas peruanas radica en el hecho de que en una época en que se necesitan héroes militares para restituir la dignidad nacional perdida, el sufrimiento, “carcoma y lepra de la vida”, “afemina” al sujeto republicano, colocándolo en una posición de vencido más que de vencedor. Dice:

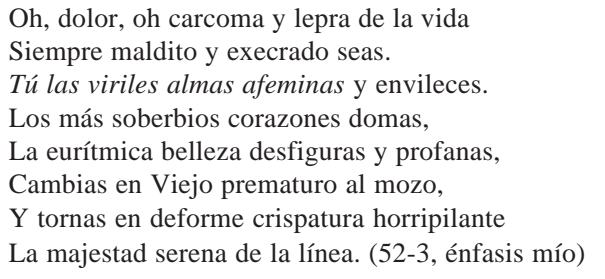

El antisentimentalismo del González Prada tardío puede leerse en términos historiográficos, como una respuesta a la frustración por la pérdida de la guerra en la que la única posibilidad de recuperar Arica y Tacna es por medio de la militarización de la otredad indígena. El efecto que la guerra tiene en el pensamiento de González Prada queda registrado en un ensayo biográfico sobre Grau, cuando dice que "[l]a guerra, con todos sus males, nos hizo el bien de probar que todavía sabemos engendrar hombres de temple viril” (41). El sufrimiento indígena, que antes de la guerra del Pacífico le resultaba semánticamente productivo a la hora de construir identidades masculinas, se vuelve ahora una esencia debilitante contra la que hay que luchar porque “[m]ás vale ser hierro que nube” (Páginas 18) Por otro lado, el deseo de combatir el sentimentalismo es también un síntoma del pánico que genera en la esfera estética masculina la aparición de la femme des lettres. La ideología de la masculinidad hiperviril que González Prada configura en los ensayos se define a través de una afirmación de la diferencia y superioridad del sujeto masculino criollo en términos de género y raza. En este sentido, las ideas de González Prada sobre la masculinidad y la virtud cívica son construcciones culturales que van cambiando y oscilando de acuerdo a la necesidad histórica de los tiempos. La alianza homo-sentimental entre sujeto criollo e indígena que González Prada idealiza en las Baladas peruanas se vuelve conflictiva en los ensayos. Más que humanizar al indígena por medio de un proceso de sentimentalización González Prada propone una utopía marcial en la que indígenas y dandies deben unirse para modernizar y defender a la nación debilitada. 
Adams, James Eli. Dandies and Desert Saints: Styles of Victorian Masculinity. Ithaca: Cornell University Press, 1995.

Balta, Aída. Presencia de la mujer en el periodismo escrito peruano (1821-1960). Lima: San Martín de Porres, 1998.

Baudelaire, Charles. "Le peintre de la vie moderne”. Balzac, Baudelaire, Barbey D’Aurevilly: sur le dandysme. Olivier de Magny, ed. Paris: Union Général, 1971. 189-246.

Journaux Intimes: Fusées-Mon Coeur Mis a Nu-Carnet. Jacques Crépet et Georges Blin, eds. Paris: Librairie José Corti, 1949.

Berg, Mary. "Presencia y ausencia de Clorinda Matto de Turner en el panorama literario y editorial peruano”. Edición e interpretación de textos andinos. Ignacio Arellano y José Mazzotti, eds. Madrid/Frankfurt: Iberoamericana/Veuvert, 2000.

Cornejo Polar, Antonio. La formación de la tradición literaria en el Perú. Lima: CEP, 1989.

Chang-Rodríguez, Eugenio. “Manuel González Prada”. Historia de la literatura hispanoamericana. Luis Iñigo-Madrigal, ed. Madrid: Cátedra, 1982. I: 473-86.

Chapman, Mary \& Glenn Hedler. Sentimental Men. Masculinity and the Politics of Affect in American Culture. Berkeley: University of California Press, 1999.

Douglass, Ann. The Feminization of American Culture. New York: Avon, 1978.

Denegri, Francesca. El abanico y la cigarrera: La primera generación de mujeres ilustradas en el Perú. Lima: Flora Tristán, 1998.

Ferrari, Américo. “Manuel González Prada entre lo Nuevo y lo Viejo”. Lectura crítica de la literatura Americana: la formación de las culturas nacionales. Saúl Sosnowski, ed. Caracas: Ayacucho, 1996. II: 317-35.

Fisher, Philip. Hard Facts: Setting and Form in the American Novel. New York: Oxford University Press, 1985.

García Salvatecci. Visión de un apóstol. Pensamiento del Maestro González Prada. Lima: Emisa, 1990.

González Prada, Manuel. Presbiterianas. Lima: El Inca, 1928. Baladas peruanas. Santiago: Ercilla, 1935. Grafitos. Paris: Tipografía de Louis Bellenand et Fils, 1937. Nuevas páginas libres. Santiago: Ercilla, 1937. Antología poética. México: Cultura, 1940. Exóticas / Trozos de vida. Lima: P.T.C.M., 1948. Páginas libres / Horas de lucha. Barcelona: Ayacucho, 1985.

González Stephan, Beatriz. "Héroes nacionales, estado viril y sensibilidades homoeróticas”. Estudios 12 (1998): 83-121.

Gorriti, Juana Manuela. “El tesoro de los Incas”. Sueños y realidades. Tomo II. Buenos Aires: Casavalle, 1865.

Higgins, James. A History of Peruvian Literature. Liverpool: Francis Cairns, 1987.

Hinterhaüser, Hans. Fin de siglo: figuras y mitos. Madrid: Taurus, 1998. 
Kristal, Efraín. The Andes Viewed From the City. Literary and Political Discourse on the Indian in Peru 1848-1930. New York: Peter Lang, 1987.

Lasarte, Javier. "Pueblo y mujer: figuraciones dispares del intelectual modernista (Martí y González Prada)”. Delmira Agustini y el modernismo. Nuevas propuestas de género. Tina Escaja, ed. Rosario: Beatriz Viterbo, 2000.

Ludmer, Josefina. El cuerpo del delito. Un manual. Buenos Aires: Perfil, 1999.

Mariátegui, José Carlos. Siete ensayos de interpretación de la realidad peruana. [1928] Lima: Era, 1979.

Martí, José. Obras completas. Poesía. Vol. 17. La Habana: Editorial Nacional, 1964.

Matto de Turner, Clorinda. Hima-Sumac. Lima: Impr. La equitativa, 1892.

Montaldo, Graciela. La sensibilidad amenazada. Fin de siglo y modernismo. Rosario: Beatriz Viterbo, 1994.

Moraña, Mabel. “José Enrique Rodó”. Historia de la literatura hispanoamericana.Luis Iñigo-Madrigal, ed. Madrid: Cátedra, 1982. I: 655-65.

Peluffo, Ana. "El poder de las lágrimas: Sentimentalismo, género y nación en Aves sin nido de Clorinda Matto de Turner”. Indigenismo hacia el fin del milenio: homenaje a Antonio Cornejo Polar. Mabel Moraña, ed. Pittsburgh: IILI, 1998. 119-38.

“Decadentismo y necrofilia: el culto a la amada muerta en la poesía de fin de siglo”. Ficciones y silencios fundacionales: literaturas y culturas post-coloniales en América Latina. Friedhelm Schmidt, ed. Frankfurt/Madrid: Iberoamericana/Veurvert, 2003. 239-53.

"Why Can’t An Indian Be More Like A Man?: Sentimental Bonds in Clorinda Matto de Turner and Manuel González Prada”. Revista de Estudios Hispánicos 38 (2004): 3-21.

“Homo-sentimentalismo, fraternidad y lágrimas en José Martí”. Confluencia 21 [en prensa Fall, 2005]

Ramos, Julio. Desencuentros de la modernidad en América Latina. México: FCE, 1989.

Riva Agüero, José. Carácter de la literatura del Perú independiente. Lima: Univ. Católica del Perú, 1962.

Sánchez, Luis Alberto. La literatura peruana. Tomo III. Lima: Ediventas, 1965. Mito y realidad de González Prada. Lima: Villanueva, 1976.

Prólogo a Baladas Peruanas de Manuel González Prada. Santiago: Ercilla, 1935. 9-21.

Salazar Bondy, Augusto. Historia de las ideas en el Perú contemporáneo. Tomo I. Lima: Moncloa, 1967.

Sarlo, Beatriz. El imperio de los sentimientos: narraciones de circulación periódica en la Argentina. 1917-1927. Buenos Aires: Catálogos, 1985.

Tamayo Vargas, Augusto. Literatura peruana. Tomo II. Lima: Peisa, 1992.

Showalter, Elaine. Sexual Anarchy: Gender and Culture at the Fin de Siécle. New York: Viking, 1990.

Schwarz, Roberto. Misplaced Ideas. John Gledson, trad. London/New York: Verso, 1992.

Sommer, Doris. Foundational Fictions: The National Romances of Latin America. Berkeley: University of California Press, 1991. 